\title{
Peutz-Jeghers syndrome: Four cases in one family
}

\author{
Ran Wang ${ }^{1,2}$, Xingshun $\mathbf{Q i}^{1, *}$, Xu Liu ${ }^{1}$, Xiaozhong Guo ${ }^{1,2, *}$ \\ 'Department of Gastroenterology, General Hospital of the Shenyang Military Area, Shenyang, China; \\ ${ }^{2}$ Postgraduate College, Liaoning University of Traditional Chinese Medicine, Shenyang, China.
}

\begin{abstract}
Summary Peutz-Jeghers syndrome (PJS) is a rare, but life-threatening, familial inherited disease, characterized by mucocutaneous pigmentation and hamartomatous polyps. The estimated incidence of PJS ranges from $1 / 50,000$ to $1 / 200,000$. PJS can significantly increase the risk of malignancies, and especially gastrointestinal malignancies. Reported here are 4 cases of PJS in one family.
\end{abstract}

Keywords: Peutz-Jeghers syndrome, hamartomatous polyp, malignancy

\section{Introduction}

In 1921, Peutz first reported a case of a Dutch family with multiple polyps throughout the gastrointestinal tract and mucocutaneous pigmentation. In 1949, Jeghers et al. reported 10 cases involving similar complaints and they noted a connection between multiple polyps and pigmentation. Peutz-Jeghers syndrome (PJS) is a rare, but life-threatening, familial inherited disease $(1,2)$. The estimated incidence of PJS ranges from $1 / 50,000$ to $1 / 200,000$. PJS can significantly increase the risk of malignancies, and especially gastrointestinal malignancies (3). Reported here are 4 cases of PJS in one family.

\section{Case report}

On April 2015, a 22-year-old male was admitted to this department for intermittent abdominal discomfort and diarrhea. The young man had scattered black spots on his lips and fingers. Eight years ago, he was diagnosed with intestinal obstruction due to multiple polyps in his small intestine and he underwent intestinal resection at a local hospital. PJS was diagnosed. Computed tomography scans of the abdomen (Figure 1) and

Released online in J-STAGE as advance publication November 20, 2015.

*Address correspondence to:

Dr. Xiaozhong Guo and Dr. Xingshun Qi, Department of Gastroenterology, General Hospital of the Shenyang Military Area. No. 83 Wenhua Road, Shenyang 110840, China.

E-mail: guo xiao zhong@126.com (Guo XZ); xingshunqi@126. com (Qi XS) colonic endoscopy and upper gastrointestinal endoscopy (Figure 2) at admission to this Department revealed a number of large polyps. The maximum length of polyps in the transverse colon was $12 \mathrm{~cm}$. Subsequently, the patient underwent endoscopic polypectomy. Histology confirmed the presence of inflammatory polyps (Figure $3)$. The patient was discharged without problem.

On June 2015, his cousin, a 19-year-old girl, was also admitted to this Department for colonic endoscopy. The girl had slight mucocutaneous pigmentation on her lips and fingers. She was diagnosed with PJS by a local hospital and intussusception was noted, so she underwent intestinal resection in 2012. Histology confirmed the presence of hamartomatous polyps. Upon admission, the polyps were treated via a doubleballoon endoscopic polypectomy. The patient refused to undergo subsequent histological examinations, and she was discharged without problem.

After a detailed survey of 14 members of the original patient's family, his father and uncle were also diagnosed with PJS. His father died of a post-operative infection at the age of 30 . His uncle died of lung adenocarcinoma at the age of 44 . His cousin was alive and age 19. Other family members had no symptoms or signs of PJS (Figure 4). The original patient and his cousin are being followed with regular endoscopic examinations.

\section{Discussion}

PJS is an autosomal dominant disease with no significant difference in the gender or race of individuals it affects. Patients with PJS have different complications such as obstruction, intussusception, and anemia (4).The treatment of PJS often depends on 


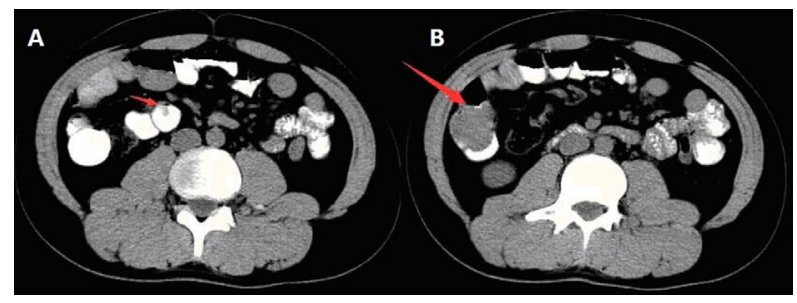

Figure 1. Computed tomography scans of the abdomen. Red arrows point to polyps.

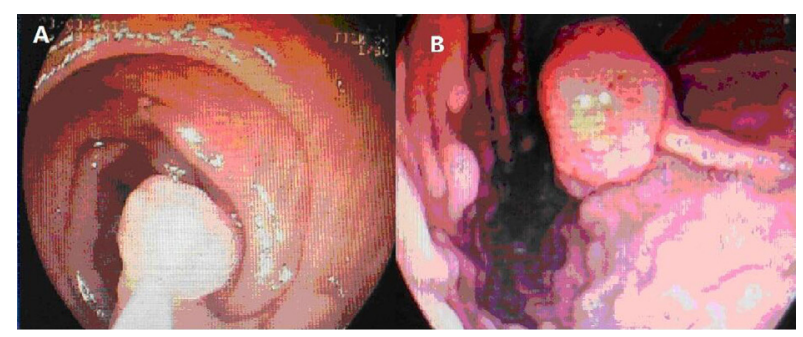

Figure 2. Endoscopic examination. (A), Colonic polyp; (B), Gastric polyp.

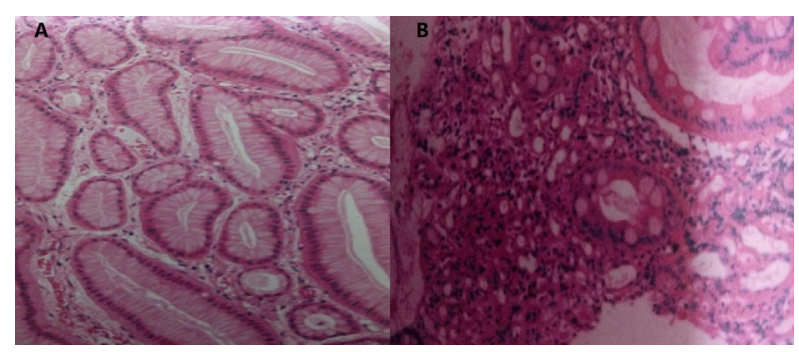

Figure 3. Histological examination. (A), Gastric histology confirmed the presence of inflammatory polyps; (B), Colonic histology confirmed the presence of inflammatory polyps.

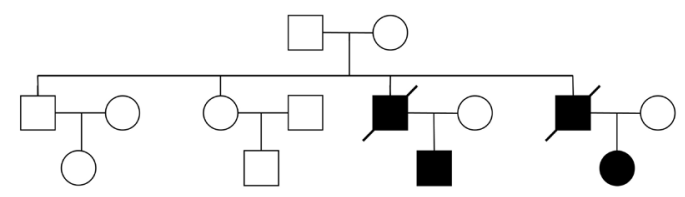

Figure 4. Family tree. A square refers to a male and a circle refers to a female. A slash indicates a person who has died.

those complications. Laser therapy can be used to treat pigmentation if the patient so desires. Double-balloon endoscopy allows both examination and treatment of polyps. A timely polypectomy with double-balloon endoscopy can reduce the need for abdominal surgery and consequent problems in patients with PJS (5).

The WHO diagnostic criteria for PJS include: $i) \geq 3$ hamartomatous polyps; ii) hamartomatous polyps and a family history of PJS; iii) mucocutaneous pigmentation and a family history of PJS; or $i v$ ) mucocutaneous pigmentation and hamartomatous polyps (6). Hamartomatous polyps were considered to be benign lesions, but there is uncertainty as to whether or not PJS-associated hamartomas were pre-malignant in PJS.
Some researchers believe that PJS is an epiphenomenon preceding a cancer-prone state $(7,8)$. In contrast, some researchers hypothesize that PJS polyps follow the hamartoma-carcinoma sequence, leading to a high risk of malignancy $(3,7)$. Three of the family members studied here had hamartoma polyps that were confirmed histologically, but one only had inflammatory polyps. One family member had hamartomatous polyps that were confirmed histologically and eventually died of lung adenocarcinoma. Inflammatory polyps, hamartomatous polyps, and lung adenocarcinoma were found in one family. Thus, PJS polyps may follow the hamartomacarcinoma sequence. A further follow-up study of this family is needed to prove this hypothesis.

Further screening for the $S T K 11 / L K B 1$ gene mutation should help to evaluate the risk of malignant transformation in two young survivors (9). However, both patients refused genetic testing. Clearly, a close follow-up with physical examinations and endoscopy is recommended.

\section{References}

1. Beggs AD, Latchford AR, Vasen HF, et al. Peutz-Jeghers syndrome: A systematic review and recommendations for management. Gut. 2010; 59:975-986.

2. Giardiello FM, Trimbath JD. Peutz-Jeghers syndrome and management recommendations. Clin Gastroenterol Hepatol. 2006; 4:408-415.

3. van Lier MG, Wagner A, Mathus-Vliegen EM, Kuipers EJ, Steyerberg EW, van Leerdam ME. High cancer risk in Peutz-Jeghers syndrome: A systematic review and surveillance recommendations. Am J Gastroenterol. 2010; 105:1258-1264.

4. Kopacova M, Tacheci I, Rejchrt S, Bures J. PeutzJeghers syndrome: Diagnostic and therapeutic approach. World J Gastroenterol. 2009; 15:5397-5408.

5. Oncel M, Remzi FH, Church JM, Connor JT, Fazio VW. Benefits of 'clean sweep' in Peutz-Jeghers patients. Colorectal Dis. 2004; 6:332-335.

6. Higham P, Alawi F, Stoopler ET. Medical management update: Peutz Jeghers syndrome. Oral Surg Oral Med Oral Pathol Oral Radiol Endod. 2010; 109:5-11.

7. Retrosi G, Nanni L, Vecchio FM, Manzoni C, Canali R, Busato G, Pintus C. Solitary Peutz-Jeghers polyp in a paediatric patient. Case Rep Gastroenterol. 2010; 4:452456.

8. Jansen M, de Leng WW, Baas AF, Myoshi H, MathusVliegen L, Taketo MM, Clevers H, Giardiello FM, Offerhaus GJ. Mucosal prolapse in the pathogenesis of Peutz-Jeghers polyposis. Gut. 2006; 55:1-5.

9. Syngal S, Brand RE, Church JM, Giardiello FM, Hampel HL, Burt RW. ACG clinical guideline: Genetic testing and management of hereditary gastrointestinal cancer syndromes. Am J Gastroenterol. 2015; 110:223-262; quiz 263.

(Received September 12, 2015; Revised October 28, 2015; Accepted November 9, 2015) 